\title{
Analysis of the Particle Characteristics of Aeolian Sand in Yulin Area, China
}

\author{
Qinglong You $\mathbb{D}^{1,2}$ Zhang Yang, ${ }^{1}$ Jinglian Ma, ${ }^{3}$ Xili Yan, ${ }^{2}$ Taiwo Sesay $\mathbb{D}^{2}{ }^{2}$ Haifeng Wang, \\ and Zhou Liang ${ }^{5}$ \\ ${ }^{1}$ Key Laboratory of Degraded and Unused Land Consolidation Engineering, The Ministry of Natural Resources of China, \\ Xi'an 710075, China \\ ${ }^{2}$ School of Highway, Chang'an University, Xi'an 710064, China \\ ${ }^{3}$ School of Management, Xi'an University of Finance and Economics, Xi'an 710100, China \\ ${ }^{4}$ School of Civil Engineering, Yantai University, Yantai, Shandong 264003, China \\ ${ }^{5}$ Transport Planning and Research Institute, Ministry of Transport, Beijing 100028, China
}

Correspondence should be addressed to Qinglong You; youqinglong0730@163.com

Received 26 August 2021; Revised 29 November 2021; Accepted 15 January 2022; Published 14 February 2022

Academic Editor: Piotr Smarzewski

Copyright ( 92022 Qinglong You et al. This is an open access article distributed under the Creative Commons Attribution License, which permits unrestricted use, distribution, and reproduction in any medium, provided the original work is properly cited.

Aeolian sand is an important construction material in many desert regions. In order to study its engineering properties, samples were extracted from two sections within Yulin city, Shaanxi province of China. One set was collected from a site along the G210 highway that connects Yulin city and Inner Mongolia, and the other sampling site was along the provincial highway S204 that connects Yulin and Jingbian city. Sieve analyses using square mesh and round mesh sieves were conducted to determine the particle size distribution of the collected sand samples. In addition, scanning electron microscopy (SEM) and X-ray diffraction (XRD) were used to characterize the surface microstructure and mineral composition of the sand particles, respectively. Based on the sieve analyses results, the size distribution of the Aeolian sand particles in this region is mainly between $0.075 \mathrm{~mm}$ and $0.3 \mathrm{~mm}$ with low clay content $(0.69-10.3 \%)$. Also, it was found that the square mesh is more effective than the round mesh for conducting sieve analysis of Aeolian sand, with the $0.15 \mathrm{~mm}$ sieve identified as the key sieve size. Using the percentage passing rates in the $0.15 \mathrm{~mm}$ square sieve as a classification index, the particle gradation of the sand particles was simplified into three classes: Class A (less than 30\%), Class B (between 30\% and 60\%), and Class C (more than 60\%). SEM observation revealed different profile configurations on the surfaces of the Aeolian sand particles including intensive pitting, corrosion marks, and cracks, while the XRD results indicated the presence of quartz and feldspar in more than $95 \%$ of the entire mineral composition of the sand particles. Minerals that are deleterious to cement and mortar used in road construction were present in negligible amounts. From the particle size characterization, it is possible to use Aeolian sand as a subgrade material in road construction due its lower clay content. Also, the negligible amount of minerals such as calcite and chlorite in the Aeolian sand mineral composition indicates its potential for use in cement and mortar without causing any complex chemical reactions. The findings of this study indicate the possibility of utilizing the Aeolian sand deposits in Yulin area as a road construction material and also provide a theoretical guide to encourage its widespread application in this regard.

\section{Introduction}

The total land surface area of the Earth is about 57,308,738 square miles, of which about one-third is desert [1]. In China, deserts occupy approximately 27 percent of the entire country's landmass which extends by nearly 500,000 miles from northern China to southern Mongolia [2]. Most part of
Inner Mongolia (an autonomous region of China) is a plateau covered by extensive Aeolian sand deposits.

Aeolian sand refers to grains of sand that are being eroded, transported, and deposited as a result of air movements over Earth's surface. Wind erosion of the sand particles is undesirable to the environment, and according to Li et al. [3], the particle characteristics of Aeolian sand can 
play a significant role in reducing its adverse effects on the environment. During the formation of windblown sediments, the individual grains are transported by surface creep (rolling), suspension, and saltation (bouncing) [4, 5], and depending on the dominant transport process, four groups of sand sediments can be formed-poorly sorted, moderate to well sorted, Aeolian silt (loess), and fine-grained Aeolian dust [6]. Elipe and López-Querol [7] collected Aeolian sand samples from different locations and classified them using ASTM and AASHTO classification systems. The results based on the ASTM system classified the sand samples into poorly graded sand (SP) or poorly graded sand with silt (SP$\mathrm{SM})$, whereas, in accordance with the AASHTO classification system, the sand particles were classified as A-1, A-2, and A-3 [7]. In China, even though variations exist in the physical features of the sand deposits due to regional difference [8], the sands are generally poorly graded with great uniformity, which can be due to the sorting of the wind.

To understand the origin and properties of Aeolian sand, characterization of their mineral composition and surface microstructure is crucial. Commonly used methods for this purpose include the XRD technique which analyzes mineral composition and the SEM technique which examines the particle surface morphology $[9,10]$. Aeolian sands from different locations are mainly composed of mineral silica and, in minority, feldspars and other minerals such as calcite $[11,12]$. This is particularly important because quartz and feldspars are minerals that can be exploited for numerous industrial uses [13]. Meanwhile, SEM examination of Aeolian sand particles revealed that there is variability in the mechanically and chemically formed surface textures [14]. The surface texture and mineral composition gives an indication of the weathering history of the sediments, their origin, and type. For example, the weathering of quartz-rich rocks, especially granites and sandstone, results in the formation of dune sediments which are dominated by quartz and feldspar [15].

For proper classification of Aeolian sand sediments, it is also very important to understand their individual grain properties and grain size distribution. According to El-Sayed [16], air-transported grains are generally rounded, because the grains are intensively subjected to pitting and become rounded quickly. Yuan et al. [17] conducted sieve analysis on samples collected from different locations including the Yulin transit line of $\mathrm{Mu}$ Us Desert. The results indicate that the grain particle sizes mostly range from $0.25 \mathrm{~mm}$ to $0.074 \mathrm{~mm}$, and samples from Yulin transit line of $\mathrm{Mu}$ Us Desert were found to have a particle size distribution of 0.074-0.600 mm. Zhang et al. [18] also obtained similar results after analyzing the gradation characteristics of Aeolian sand particles from Khorchin desert area in Inner Mongolia.

Yulin is a city in China which is bordered by Inner Mongolia to the north, Shaanxi to the east, Yan'an to the south, Wuzhang to the west, and the Ordos desert to the north and northwest. It has a climate that is semiarid with very cold, long winters, hot summers, and great diurnal temperature variations. In recent years, various highway construction projects have been undertaken within the region including the G210 highway that connects Yulin city and Inner Mongolia and the provincial highway S204 that connects Yulin and Jingbian city. The construction materials used in these projects are mainly transported from other regions within the country which incurs high costs. Although Aeolian sand is the most abundant material in this region, its use as a fine aggregate material in road construction has not yet been explored. This can be due to lack of sufficient research to provide necessary information on its particle characteristics. Particle characteristics, such as shape, size, and microstructure, directly influence the final properties of a material, and besides, previous studies have shown that Aeolian sand can be successfully used as a fine aggregate material in cement mortar or concrete for different civil engineering applications including highway construction [12, 19-22]. Encouraging the widespread use of Aeolian sand deposits in Yulin will yield tremendous benefits both economically and socially.

Therefore, the purpose of this study is to analyze the particle characteristics of Aeolian sand deposits and to provide a theoretical guide for its possible application in highway construction. Specifically, this study will focus on the size and gradation, surface morphology, and mineral composition of the sand particles. Also, this study seeks to develop a simplified system for classifying the sand particles based on gradation analysis.

\section{Experimental Study}

2.1. Study Site and Sampling Method. The current study is in support of ongoing projects that includes the reconstruction and expansion of two sections within Yulin city, namely, the Shaanxi-Mongolia section of the G210 highway (Yulin to Inner Mongolia boundary) and the Yu-Jing section of the S204 highway (Yulin to Jingbian). Highway G210 begins from Yu Yang Guo Guy field, in Shaanxi province to the Inner Mongolia border. It is a secondary road project with a total length spanning $83.1 \mathrm{~km}$ along the south-east edge of the Maowusu sandy land. Its overall geographical morphology comprises sand undulating dunes with diluvia plain shoal and three types of valley terrace. The sand-wave dune mainly consists of fixed and semifixed dunes and sand ridge with small amounts of mobile sand dunes forming an undulating terrain. Highway S204 begins from Yu Yang district, through Hengshan to Jingbian-Yanshuiguang pipeline with a total length of $123.6 \mathrm{~km}$. About $61 \mathrm{~km}$ of the $S 204$ road runs from Yulin city to Hengshan, while the rest is concentrated along the southeast edge of Maowusu sandy land and in the bordering area of the loess plateau. The entire region is characterized by grass land and hilly gully region with a wide distribution of Aeolian sand deposits.

Due to variations in topography, geomorphic conditions, and nonuniformity of soil characteristics, Aeolian sand samples were extracted from three strategic locations at each sampling site. Table 1 shows the sample number and changes of the three sample collection points along the Shaan-Mongolia section of highway G210 and the Yu-Jung section of highway S204, respectively. At each location, about $70,700 \mathrm{~cm}^{3}$ of sample was manually dug up to a depth 
Table 1: Sampling site of the Aeolian sand in Yulin area.

\begin{tabular}{lcc}
\hline Sand sample number & Road section & Location \\
\hline SM1 & Shaan-Mongolia section & K253+350 \\
SM2 & Shaan-Mongolia section & K263+100 \\
SM3 & Shaan-Mongolia section & K276+800 \\
YJ1 & Yu-Jing section & K33+450 \\
YJ2 & Yu-Jing section & K37+200 \\
YJ3 & Yu-Jing section & K87+000 \\
\hline
\end{tabular}

of $100 \mathrm{~cm}$ from a $30 \mathrm{~cm}$ diameter hole. Figure 1 is a photo taken of the extracted Aeolian sand in one of the sampling locations of this study.

2.2. Particle Size Characterization. The physical and chemical properties of Aeolian sand are affected by their particle size and gradation. To well characterize the Aeolian sand size distribution, collected samples were properly screened and subjected to sieve analysis using circular and square sieve meshes $(0.075 \mathrm{~mm}$ to $1.00 \mathrm{~mm}$ sizes). The purpose of using both circular and square meshes was to determine which one is more suitable for characterizing the particle size distribution of Aeolian sand. Also, using a Mastersizer 3000 (Malvern) particle size analyzer, the particle size distribution of the sand samples was further characterized based on three different diameters: (1) the Sauter mean diameter associated with the overall dispersed phase volume and the interface, (2) the diameter below which $10 \%$ of the overall droplet volume is located (Dv10), and (3) the diameter below which $90 \%$ of the overall droplet volume is located (Dv90). The Mastersizer 3000 uses the technique of laser diffraction to measure the particle size and particle size distribution of materials. It does this by measuring the intensity of light scattered as a laser beam passes through a dispersed particulate sample. This data is then analyzed to calculate the size of the particles that created the scattering pattern.

For a more in-depth particle size analysis, screening and washing method was employed to test for fines content in the Aeolian sand samples. The test was carried out following the procedures outlined in Chinese guidelines for highway engineering aggregate test methods [23].

2.3. Microstructure Characterization Using Scanning Electron Microscopy (SEM). Characterization of surface microstructure is very crucial in understanding the formation conditions of the sand deposits, which reflects their physical and mechanical properties. For example, the presence of rounded spherical grains can be due to intensive pitting on the surface microstructure of the sand particles [16]. Also, pits and grooves (formed by chemical dissolution) and silica precipitates on the surface microstructure are known to display some mechanical features such as upturned plates, shrinkage cracks, meandering ridges, stepped fracture planes and dish-shaped depressions, and conchoidal breakage patterns $[10,14]$.

To study the microstructure and surface morphology of the Aeolian sand particles, Scan Electron Microscopy (SEM) imaging technique was implemented. In the SEM technique

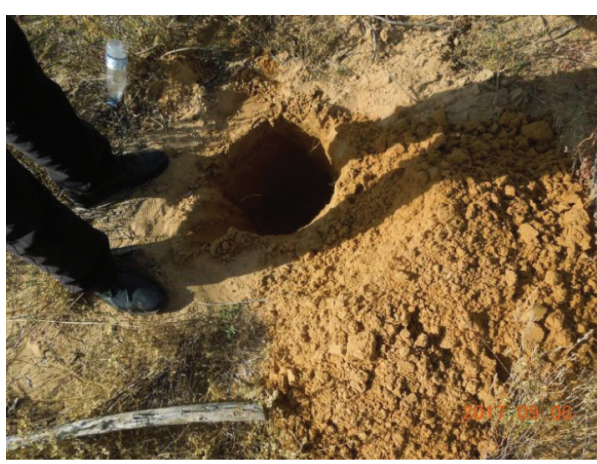

Figure 1: Extracted Aeolian sand sample.

a focused beam of electrons is applied to scan the surface of the specimen. As the beam interacts with the sample, a highresolution image is generated showing the surface morphology and composition of the sample under study. For this purpose, a Hitachi S-4800 SEM equipment was used to study the structure and morphology of Aeolian sand particles coated by a thin conductive layer of gold (10 nm thick).

2.4. Mineral Composition Analysis. The best method to identify the mineral composition of samples in the laboratory is X-ray diffraction (XRD), which is based on the constructive interference of monochromatic X-rays and a crystalline sample. Distinct XRD patterns characterized by peaks of different heights are generated as the X-rays hit the sample, which are as a direct result of the crystalline structure. In this study, XRD technique was implemented using a Bruker AXS GMBH equipment with $\mathrm{Cu} \mathrm{K} \alpha$ radiation $(\lambda)$ of $0.154 \mathrm{~nm}$, an accelerating voltage of $40 \mathrm{kV}$, and current of $30 \mathrm{~mA}$ at room temperature. The diffractograms were scanned from $5^{\circ} \mathrm{C}$ to $50^{\circ} \mathrm{C}$ at a scan rate of $0.02^{\circ}$ per 15 seconds in the $2 \theta$ range.

\section{Results and Discussion}

3.1. Particle Size Characterization. The two groups of Aeolian sand from Shaan-Mongolia section and Yu-Jing section, respectively, were screened to obtain their particle size distribution. The results obtained from the tests are shown in Table 2.

As shown in Table 2, 98.73-98.75\% of the Aeolian sand samples were mainly distributed within the range of $0.075-0.5 \mathrm{~mm}$, indicating that only $1 \%$ had sizes greater than $0.5 \mathrm{~mm}$ and less than $0.075 \mathrm{~mm}$. This agrees with the findings of Yuan et al. [17] and suggests the predominance of silty sand and fine sand in the particle composition of the Aeolian sand deposits found in this region. In addition, the diameter distribution of the sand grains and their average specific surface areas were evaluated and the results are shown in Table 3.

Based on the results shown in Table 3, the particle characteristics of two sample types are identical in terms of their diameter distribution and specific surface area. The Sauter mean diameter associated with the overall dispersed phase volume and the interface is 289 for SM1 and 281 for 
TABLE 2: Particle size distribution of Aeolian sand.

\begin{tabular}{lccccc}
\hline Number & \multicolumn{3}{c}{ Particle size distribution (\%) } \\
& $1.0-0.5$ & $0.5-0.25$ & $0.1-0.25$ & $0.1-0.075$ & 60.075 \\
\hline SM1 & 0.65 & 18.25 & 12.54 & 0.75 \\
YJ1 & 0.72 & 18.60 & 14.72 & 65.43 & 0.53 \\
\hline
\end{tabular}

TABLE 3: Diameter distribution and surface area sand particles.

\begin{tabular}{lcccc}
\hline Number & Dv10 $(\mu \mathrm{m})$ & Dv50 $(\mu \mathrm{m})$ & Dv90 $(\mu \mathrm{m})$ & Specific surface area $\left(\mathrm{m}^{2} / \mathrm{kg}\right)$ \\
\hline SM1 & 181 & 289 & 446 & 22.26 \\
YJ1 & 171 & 281 & 445 & 23.03 \\
\hline
\end{tabular}

YJ1, while their difference in specific surface area is not more than $1 \%$.

The results from the fines content analysis are presented in Table 4. As shown in Table 4, the percentage of sand samples passing through the $0.075 \mathrm{~mm}$ sieve and the clay content are not significantly different and not exceeding $11 \%$. Also, from the particle grading curve obtained from the screening test, the nonuniform coefficient $(\mathrm{Cu})$ and curvature coefficient $(\mathrm{Cc})$ were calculated to be $\mathrm{Cu}<5$ and $\mathrm{Cc}<1$, respectively. This indicates that the Aeolian sand deposits have uniform particle sizes and discontinuous grading curve, which is typical of uniform fine sand with poor gradation.

3.2. Surface Microstructure Characteristics of Aeolian Sand. The surface microstructure of the Aeolian sand samples was observed for four different particle sizes including $0.5 \mathrm{~mm}-1.0 \mathrm{~mm}, \quad 0.25 \mathrm{~mm}-0.5 \mathrm{~mm}, \quad 0.075 \mathrm{~mm}-0.25 \mathrm{~mm}$, and less than $0.075 \mathrm{~mm}$. Figures $2-5$ are the respective SEM images generated for the various particle sizes, which revealed the formation of some typical surface microstructures. As shown in Figure 2, there is a characteristic contact pore structure in the Aeolian sand particles of sizes below $0.075 \mathrm{~mm}$ and those of $075 \mathrm{~mm}-0.25 \mathrm{~mm}$. Also, they are sufficiently round with basically no salt, cement, or clay between the individual particle grains.

The images for the remaining two sizes are characterized by various surface structures including pit surface, disc pit, serpentine ridge, corrosion marks, $\mathrm{SiO}_{2}$ deposits, and cracks, as shown in Figures 3-5.

3.2.1. Pit (Frost Surface), Disc Pit, and Serpentine Ridge. As the Aeolian sand particles are being driven by the wind, they collide with each other causing the larger particles to be eroded by finer ones. The resultant effect is the formation of many small irregular pits forming a frost surface. In Figure 3, the frost surface of Aeolian sand with particle size of $0.5 \mathrm{~mm}-1.0 \mathrm{~mm}$ has been magnified 180 times under the electron microscope, while that of $0.25 \mathrm{~mm}-0.5 \mathrm{~mm}$ particle size is magnified 200 times.

Disc-shaped pits are generally concave pits with a diameter of about $50 \mu \mathrm{m}-100 \mu \mathrm{m}$ and a depth of $10 \mu \mathrm{m}-30 \mu \mathrm{m}$. They can also have a diameter of up to $200 \mu \mathrm{m}$. Figure 4 shows the disc-shaped pits on the surface of Aeolian sand with particle size $0.5 \mathrm{~mm}-1.0 \mathrm{~mm}$ and Aeolian sand of particle size $0.25 \mathrm{~mm}-0.5 \mathrm{~mm}$. Both images were obtained from electron microscope under a magnification of 180 and $200 \times$.

Snake-like ridges are formed when two or more discshaped pits converge. This type of surface microstructure was typical on Aeolian sand of particle sizes $0.5 \mathrm{~mm}-1.0 \mathrm{~mm}$ and $0.25 \mathrm{~mm}-0.5 \mathrm{~mm}$, as shown in Figure 5.

3.2.2. Corrosion Marks, $\mathrm{SiO}_{2}$ Deposits, and Cracks. Intermittent heating and cooling in desert areas do not only accelerate physical weathering of Aeolian sand, but also leave traces of chemical weathering on its surface. Quartz $\left(\mathrm{SiO}_{2}\right)$ is a chemically stable mineral that is very difficult to dissolve in water. In desert areas, there is large temperature difference between the day and night. The rapid drop in temperature at night causes the Aeolian sand particles in the condensate to contain dissolved salts, thereby slowly raising the $\mathrm{pH}$ value to 8 or 9 . The solubility of quartz slowly increases with increase in $\mathrm{pH}$ value, since only small amount of $\mathrm{SiO}_{2}$ is dissolved at the beginning. However, as the $\mathrm{pH}$ value continues to increase, the solubility of quartz also shows a gradual increasing trend. Figure 6 shows the variation of $\mathrm{SiO}_{2}$ solubility in $100 \mathrm{~g}$ of water with increase in $\mathrm{pH}$ value.

Due to the presence of an electrolyte in the solution, the surface of the Aeolian sand particles tends to condense and precipitate. As the temperature increases rapidly during the daytime, water is evaporated from the surfaces of the sand particles leaving behind $\mathrm{SiO}_{2}$ which then forms irregular shapes of opal or silica layers in small amounts. Long term deposition of $\mathrm{SiO}_{2}$ layer on the surfaces of the sand particles resulted in the formation of cracks with varying lengths. The crack lengths are usually measured in 1-50 microns and generally through several layers of the crack cleavage. Figure 7 shows the deposited $\mathrm{SiO}_{2}$ layer and cracks formed on the surfaces of Aeolian sand particles with sizes $0.25 \mathrm{~mm}-0.5 \mathrm{~mm}$ and $0.075 \mathrm{~mm}-0.25 \mathrm{~mm}$. For better visualization, the SEM images of the Aeolian sand particles with sizes $0.25 \mathrm{~mm}-0.5 \mathrm{~mm}$ are magnified by $1000 \times$, while the $0.075 \mathrm{~mm}-0.25 \mathrm{~mm}$ particles are magnified by $10000 \times$. 
TABLE 4: Fines content and gradation indexes of the different sand samples.

\begin{tabular}{lcccccc}
\hline $\begin{array}{l}\text { Sample } \\
\text { number }\end{array}$ & $\begin{array}{c}\text { Content }(\% \text { below } \\
0.075 \mathrm{~mm})\end{array}$ & $\begin{array}{c}\text { Clay }(\leq 0.02 \mathrm{~mm}) \\
\text { content }(\%)\end{array}$ & $\begin{array}{c}\text { Coefficient of } \\
\text { inhomogeneity }\end{array}$ & $\begin{array}{c}\text { Curvature } \\
\text { coefficient }\end{array}$ & $\begin{array}{c}\text { Fineness } \\
\text { modulus }\end{array}$ & Sieve passing $(\% 0.15 \mathrm{~mm})$ \\
\hline SM1 & 1.1 & 0.69 & 2.09 & 1.13 & 0.94 & 23.3 \\
SM2 & 0.8 & 0.78 & 1.90 & 0.90 & 1.32 & 7.7 \\
SM3 & 9.6 & 9.10 & 2.88 & 0.97 & 0.87 & 37.4 \\
YJ1 & 7.3 & 8.02 & 2.33 & 0.89 & 0.60 & 63.8 \\
YJ2 & 5.1 & 5.57 & 1.71 & 0.91 & 0.41 & 94.9 \\
YJ3 & 9.0 & 10.30 & 1.48 & 0.97 & 0.06 & \\
\hline
\end{tabular}

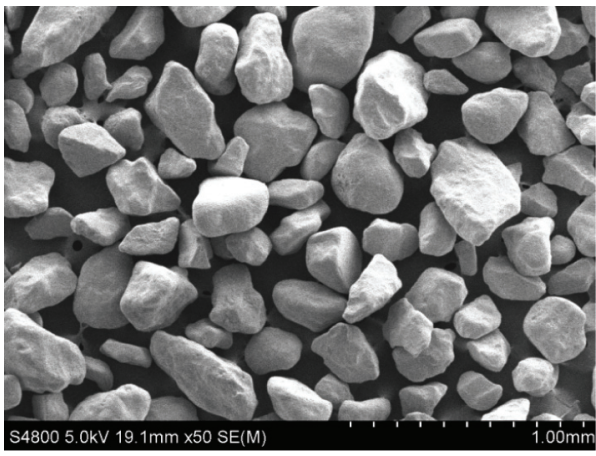

(a)

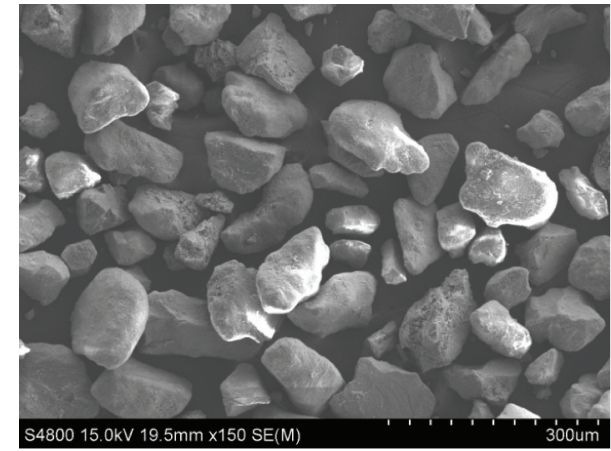

(b)

Figure 2: Contact pore structure of Aeolian sand particles. (a) 50 times larger for $0.075-0.25 \mathrm{~mm}$. (b) 150 times larger for less than $0.075 \mathrm{~mm}$.



(a)

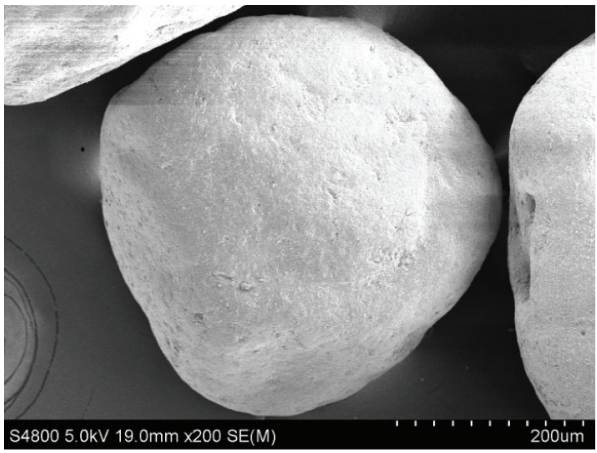

(b)

Figure 3: Frosting surface of Aeolian sand particles. (a) 180 times larger for $0.5-1.0 \mathrm{~mm}$. (b) 200 times larger for $0.25-0.5 \mathrm{~mm}$.

\section{Mineral Composition Analysis of Aeolian Sand}

In order analyze the mineral composition of the Aeolian sand deposits, XRD technique was used to generate diffraction patterns for the $0.5 \mathrm{~mm}-1.0 \mathrm{~mm}, 0.25 \mathrm{~mm}-0.5 \mathrm{~mm}$, $0.075 \mathrm{~mm}-0.25 \mathrm{~mm}$, and less than $0.075 \mathrm{~mm}$ particles, as shown in Figure 8.

The XRD patterns showed that more than $95 \%$ of the mineral components of the four groups of Aeolian sand particle sizes are mainly quartz and feldspar, with the quartz accounting for more than $50 \%$. Moreover, the quartz content in the Aeolian sand of particle sizes $0.5-1.0 \mathrm{~mm}$ is about $10 \%$ higher than that of the other three particle sizes. Also, the feldspar content constituted about $20 \%$ plagioclase and $10 \%$ feldspar, of which the proportion of plagioclase in the Aeolian sand of particle size $0.5-1.0 \mathrm{~mm}$ was about $10 \%$ less than in the other three particle sizes. In addition, calcite, dolomite, chlorite, illite, siderite, and amphibole were also detected, but their diffraction peaks were weak. Table 5 presents the percentage composition of the various minerals identified in the different Aeolian sand sizes.

\section{Engineering Classification Study}

5.1. Sieve Analysis. In order to further analyze the particle composition of Aeolian sand, two screening methods were used: the round hole sieve and square hole sieve screening. 


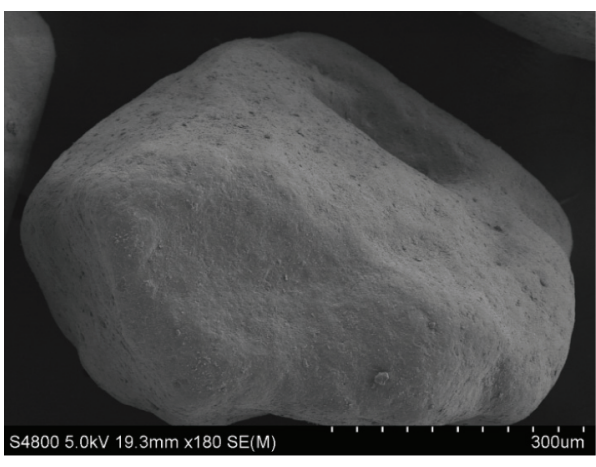

(a)

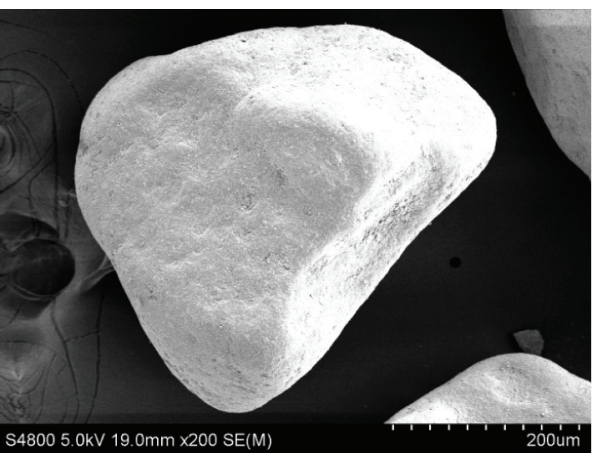

(b)

Figure 4: Disk-shaped pits on the surface of Aeolian sand particles. (a) 180 times larger for $0.5-1.0 \mathrm{~mm}$. (b) 200 times larger for $0.25-0.5 \mathrm{~mm}$.



(a)

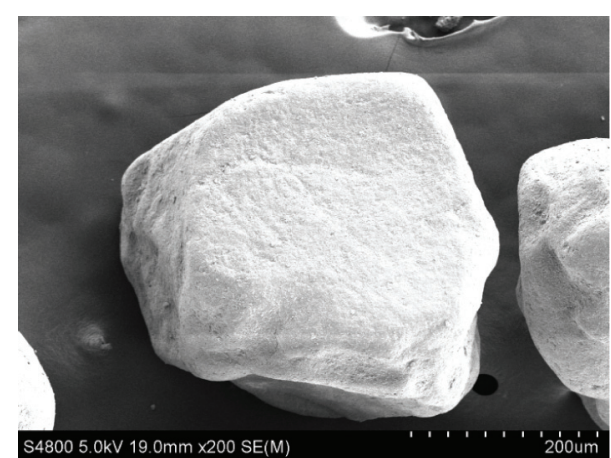

(b)

FiguRE 5: Serpentine ridges on the surface of Aeolian sand particles. (a) 180 times larger for 0.5-1.0 mm. (b) 200 times larger for $0.25-0.5 \mathrm{~mm}$.

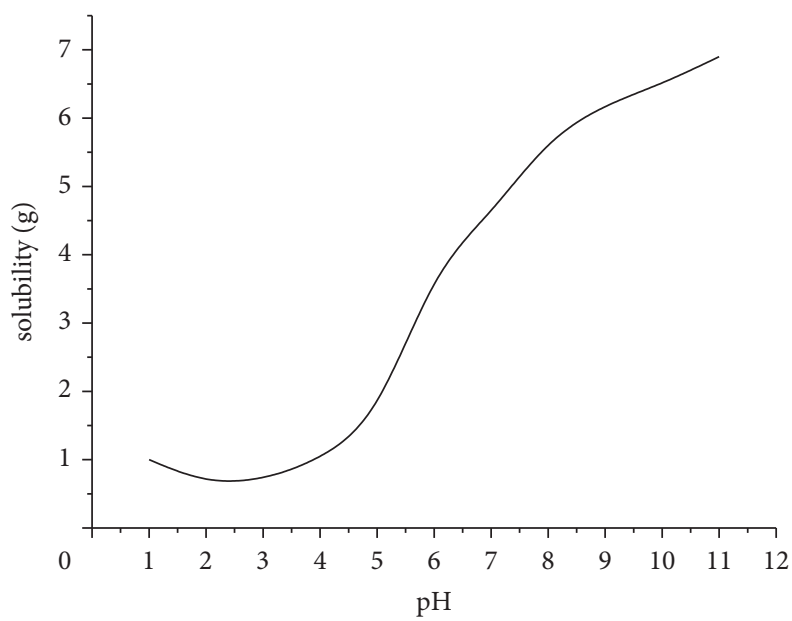

FIgURE 6: Solubility curve of $\mathrm{SiO}_{2}$ with $\mathrm{pH}$ value.

The round hole sieve screening test was conducted in accordance with the engineering classification standard for soil [24], whereas, the square hole sieve screening test was done in accordance with the "regulations of aggregate for highway engineering test" [23]. Figure 9 gives the graphical representation of the results obtained from the round sieve screening tests on the different sand samples, while Figure 10 shows the square sieve screening test results.

As shown in Figures 9 and 10, there is a clear distinction between the round and square sieve gradation curves. For the round sieve, the percentage passing rate through different sieve sizes is basically the same for all the six sample 


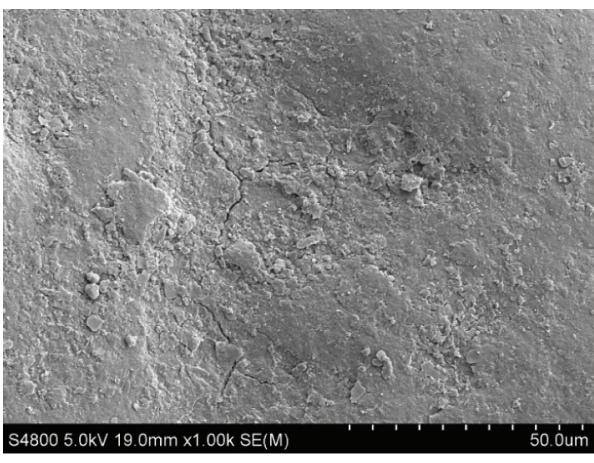

(a)

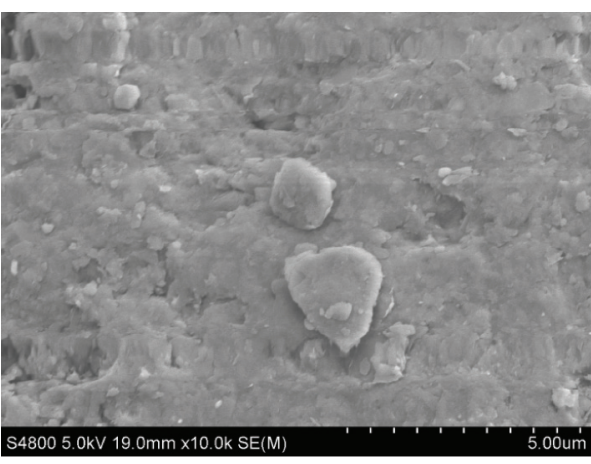

(b)

Figure 7: Surface sediment layer and crack of Aeolian sand particles. (a) 1000 times larger for $0.25-0.5 \mathrm{~mm}$. (b) 10000 times larger for $0.075-0.25 \mathrm{~mm}$.

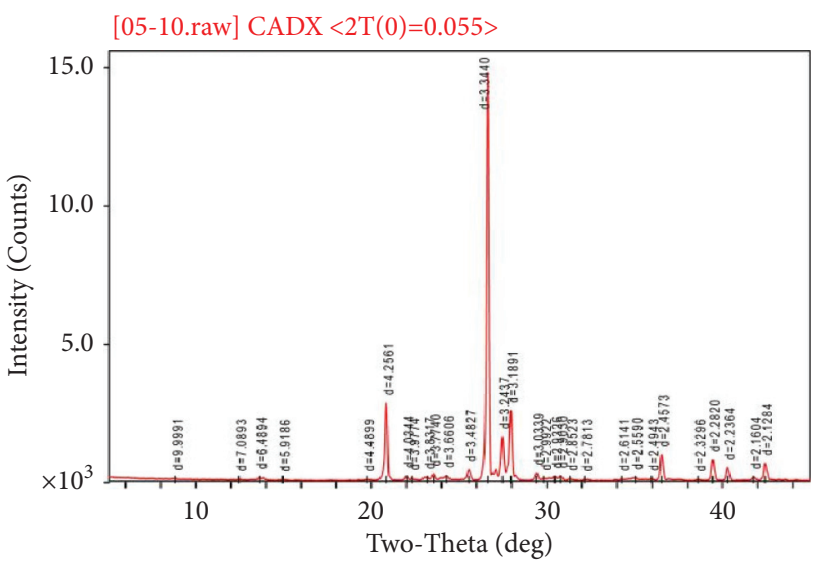

(a)

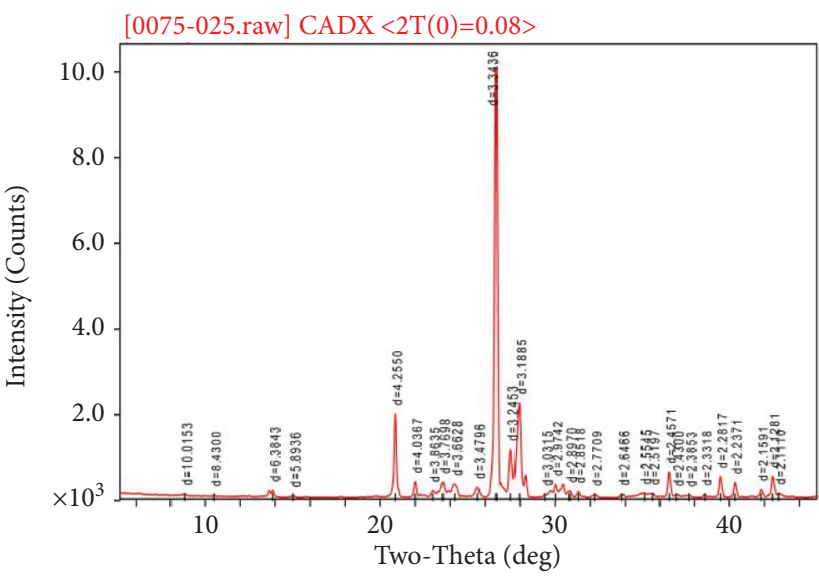

(c)

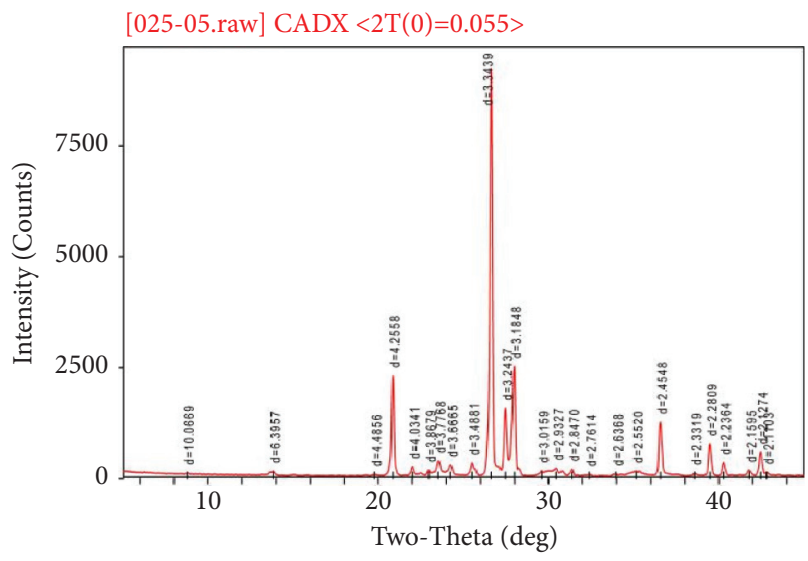

(b)

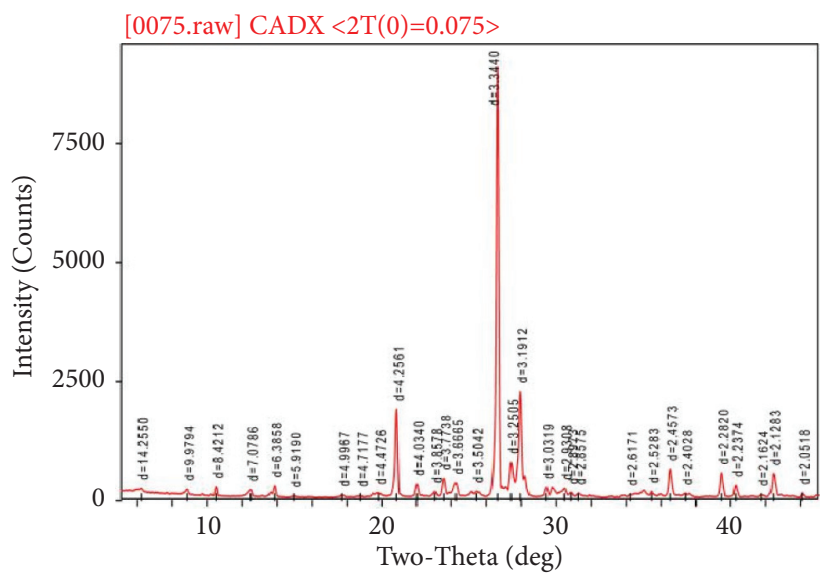

(d)

FIGURE 8: XRD patterns of Aeolian sands with four particle sizes. (a) $0.5-1.0 \mathrm{~mm}$. (b) $0.25-0.5 \mathrm{~mm}$. (c) $0.075-0.25 \mathrm{~mm}$. (d) $<0.075 \mathrm{~mm}$.

types. However, this is not the case with the square mesh sieve (Figure 10), which shows significantly different gradation for each sample type. The surface microstructure analysis indicated the presence of different forms of pitting on the surfaces of the Aeolian sand particles, which causes Aeolian sand particles to become rounded very rapidly [16]. Therefore, it can be deduced that the six Aeolian sand samples all contain predominantly rounded spherical grains. The use of round sieves to obtain the particle gradation of samples with mostly rounded grains will not yield significantly different result; however, by using a different shaped sieve such as a square hole sieve, the size distribution of different samples can be clearly distinguished. This explains why the curves in Figure 9 are identical and different from 
TABLe 5: Mineral composition of Aeolian sand with four particle sizes.

\begin{tabular}{|c|c|c|c|c|c|c|c|c|c|}
\hline \multirow{2}{*}{ Grain size $(\mathrm{mm})$} & \multicolumn{9}{|c|}{ Percentage of minerals } \\
\hline & Quartz & Plagioclase & Potassium feldspar & Calcite & Dolomite & Chlorite & Illite stone & Siderite & Amphibole \\
\hline $0.5-1.0$ & 64.4 & 20.2 & 12.6 & 0.9 & 0.6 & 0.5 & 0.5 & 0.3 & \\
\hline $0.25-0.5$ & 53.8 & 28.2 & 16.6 & & 0.9 & & 0.5 & & \\
\hline $0.075-0.25$ & 54.2 & 31.8 & 9.7 & 0.3 & 1.1 & & 1.5 & 0.6 & 0.8 \\
\hline$<0.075$ & 51.4 & 30.9 & 9.1 & 0.1 & 0.2 & 3.0 & 3.0 & & 2.3 \\
\hline
\end{tabular}

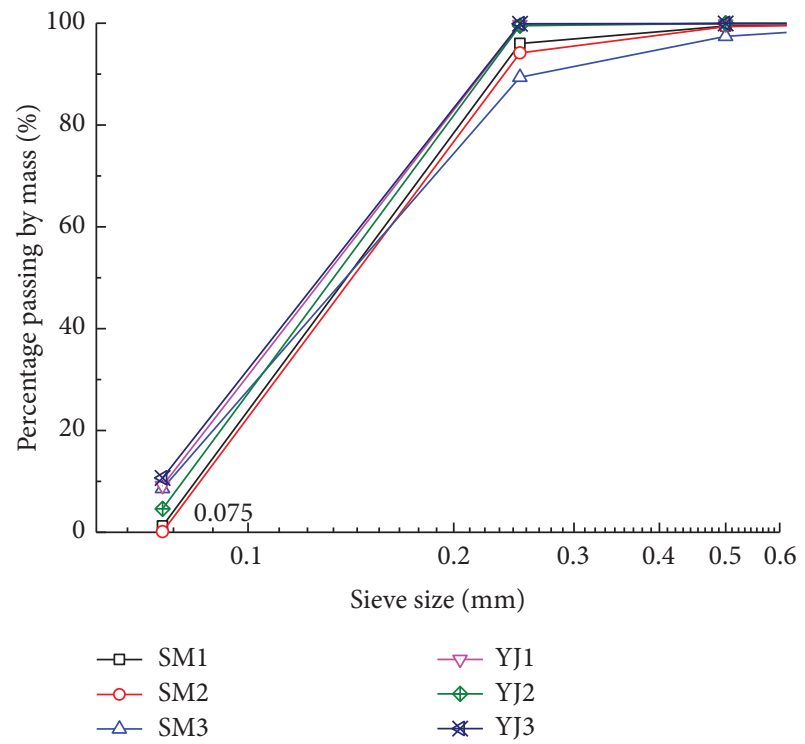

Figure 9: Round sieve curves of the different sand samples.

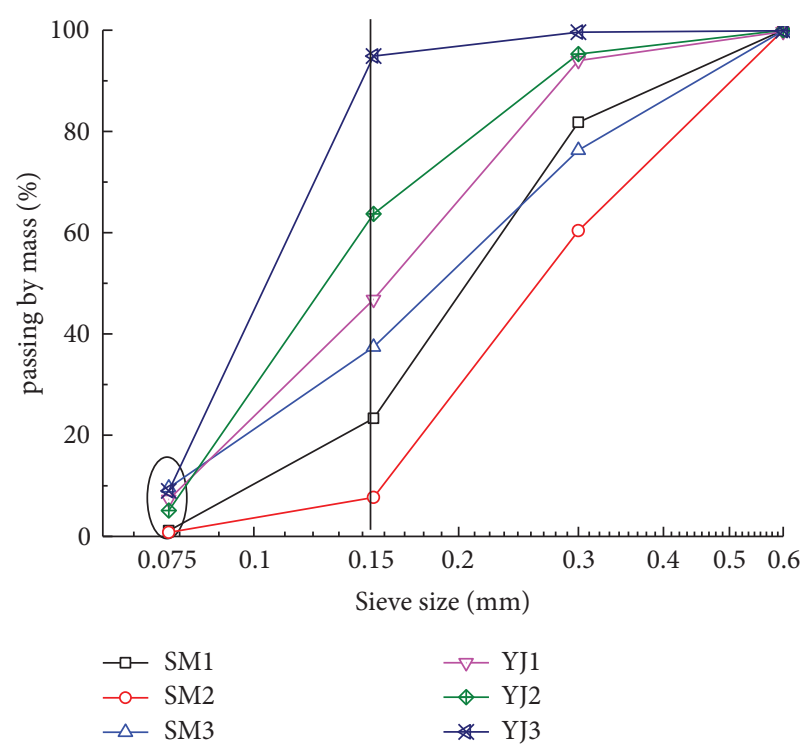

Figure 10: Square sieve curves of the different sand samples.

those in Figure 10, which shows obvious distinction in the sample gradation curves. Also, from Figure 10, the particle sizes are mainly distributed between $0.075 \mathrm{~mm}$ and $0.3 \mathrm{~mm}$, and the percentage passing in the $0.15 \mathrm{~mm}$ sieve ranges from $7 \%$ to $95 \%$ for all six samples. Based on the comparative sieve analysis results, the square hole sieve is recommended as a more suitable sieve to determine the particle gradation of the Aeolian sand deposits in Yulin. The same was also used to conduct a further classification study of the sand particles.

5.2. Analysis of Gradation Index. From the analysis given on the screening curves shown in Figure 9, the range of percentage passing of the sand samples in the $0.15 \mathrm{~mm}$ square sieve hole is large and very distinct for all the samples. Therefore, the $0.15 \mathrm{~mm}$ sieve was selected as the key sieve hole, and its passing rates were used as the classification index of Aeolian sand particles in Yulin area.

A comparison of the pass rates of the different sand samples in the $0.075 \mathrm{~mm}$ and $0.15 \mathrm{~mm}$ sieves is shown in Figure 11. From the data, it is evident that when the pass rate in the $0.15 \mathrm{~mm}$ sieve is large, the pass rate of $0.075 \mathrm{~mm}$ sieve is also large. However, the pass rate of the $0.075 \mathrm{~mm}$ shows small changes, whereas, significant variations can be noticed with the $0.15 \mathrm{~mm}$ sieve. Because of the greater sensitivity of the $0.15 \mathrm{~mm}$ sieve to percentage passing rates, it was therefore identified as the key sieve size in this study.

From the above analysis, the passing rate in the $0.15 \mathrm{~mm}$ square sieve size was selected as the more appropriate index for classifying the Aeolian sand in Yulin. The classification method begins by calculating the average of the pass rates of the six sand samples in the $0.15 \mathrm{~mm}$ sieve as $45 \%$. The calculated average value was then offset by $-15 \%$ and $+15 \%$ to obtain the values $30 \%$ and $60 \%$, respectively. By using $30 \%$ and $60 \%$ as reference points, the Aeolian sand samples were divided into three categories: Class A represents Aeolian sand with pass rate less than $30 \%$, Class B with pass rate between $30 \%$ and $60 \%$, and Class $C$ with pass rate greater than $60 \%$. The gradation curves indicating the regions of the different classified samples are shown in Figure 12.

As shown in Figure 12, Class A includes the SM1 and SM2 sand samples, Class B includes the SM3 and YJ1 samples, and Class C includes the YJ2 and YJ3 samples. Aeolian sand particles in Class B are of medium thickness, while those in Class $\mathrm{C}$ are relatively fine with high dust content.

A plot of fineness modulus, $M_{X}$ versus the $0.15 \mathrm{~mm}$ sieve pass rate, is shown in Figure 13. The fineness modulus was computed according to equation (1) as follows:

$$
M x=\frac{A_{2.36}+A_{1.18}+A_{0.6}+A_{0.3}+A_{0.15}-5 A_{4.75}}{100-A_{4.75}}
$$

where, $A_{2.36}, A_{1.18}, A_{0.6}, A_{0.3}, A_{0.15}$, and $A_{4.75}$ are cumulative percentage retained corresponding to each sieve size. 


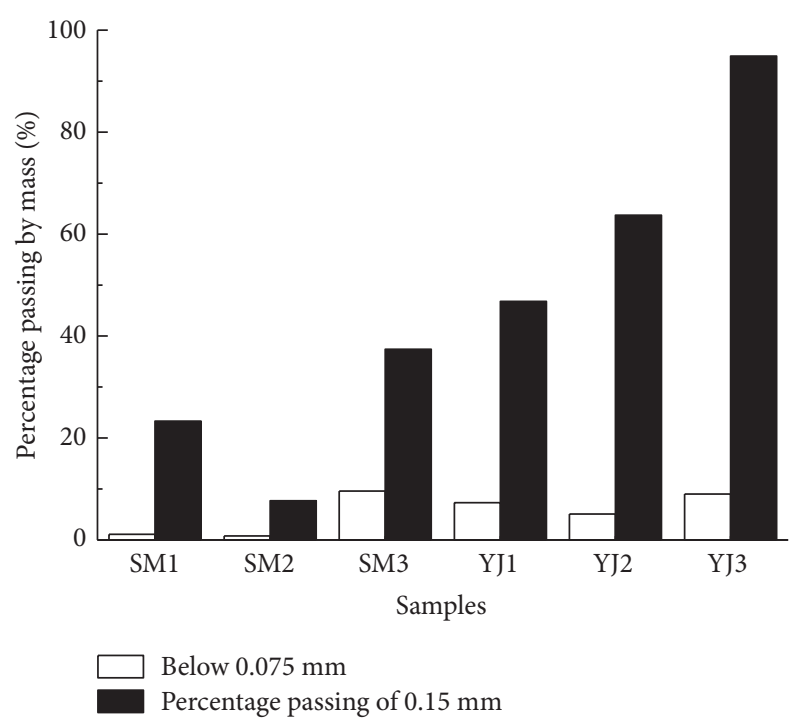

Figure 11: Passing percent in $0.075 \mathrm{~mm}$ and $0.15 \mathrm{~mm}$ sieve sizes of the different sand samples.

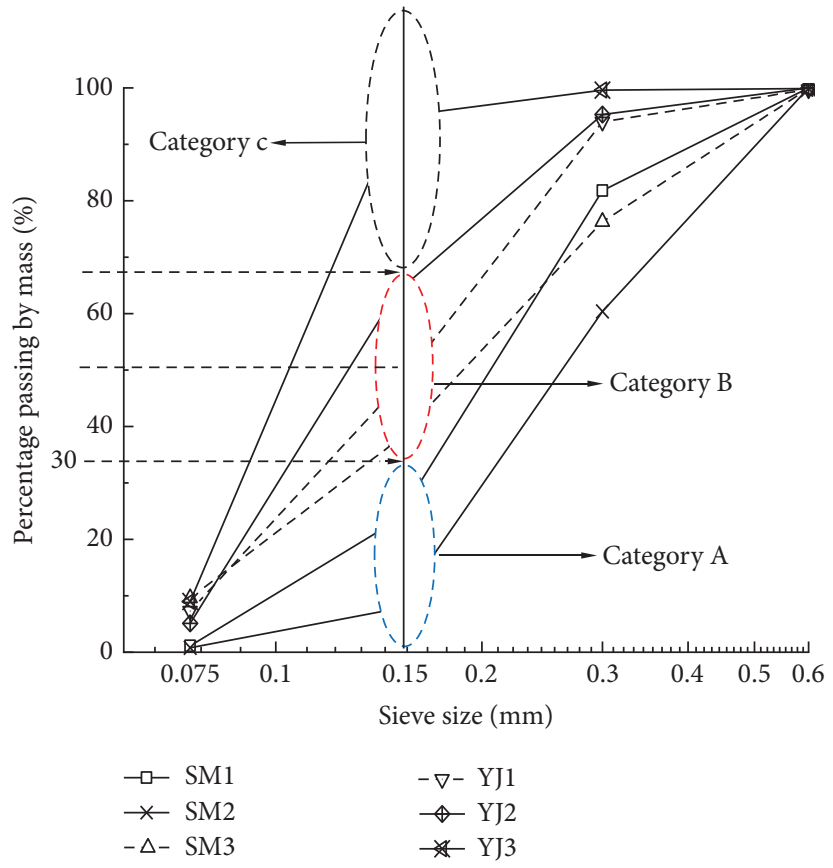

FIGURE 12: Gradation curves showing the regions of the sample classification categories.

Vertical lines are drawn through the $30 \%$ and $60 \%$ pass rates to intersect with the regression line. At the points of intersection, horizontal lines are drawn to meet the vertical axis from which the fineness modulus was obtained as 0.5 and 0.9 , respectively. In order to obtain the fineness modulus of the three classes of Aeolian sand, the fitting line is divided into representative regions $\mathrm{A}, \mathrm{B}$, and $\mathrm{C}$ as shown in Figure 13. 


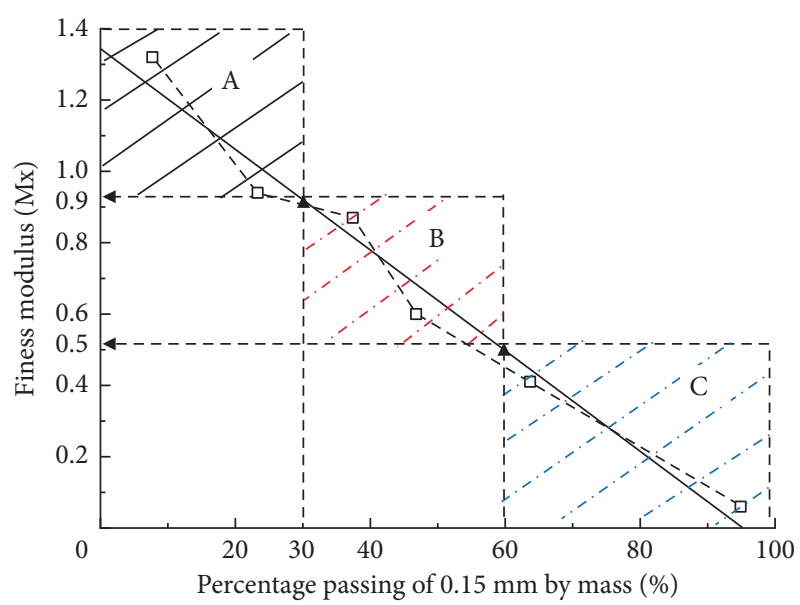

Figure 13: Classification methods of the Aeolian sand with fineness modulus.

TABLe 6: Classification results of the Aeolian sand.

\begin{tabular}{lccc}
\hline Types of Aeolian sand & Sand sample number & $0.15 \mathrm{~mm}$ pass rate (\%) & Fineness modulus $M_{x}$ \\
\hline Class A & SM1, SM2 & $30 \%$ & $0.9 \sim 1.4$ \\
Class B & SM3, YJ1 & $30 \sim 60 \%$ & $0.5 \sim 0.9$ \\
Class C & YJ2, YJ3 & $>60 \%$ & $0 \sim 0.5$ \\
\hline
\end{tabular}

Table 6 shows the fineness modulus of the three sample classes determined from Figure 12. The measured fineness modulus of each sand sample is within the range of fitted fineness modulus $M_{x}$, which was used to validate the classification results.

\section{Conclusion}

Aeolian sand is the most abundant natural resource in Arid region of Northwest China. In recent years, major road construction projects have been undertaken in this part of the country, including the G210 highway that connects Yulin city and Inner Mongolia and the provincial highway S204 that connects Yulin and Jingbian city. The raw materials used in these projects are mainly transported from other regions of country which leads to additional costs and in some cases can cause delay. Although Aeolian sand is abundantly distributed in this region, its use in road construction is not very common. This may be due to lack of sufficient information on its particle characteristics or lack of standard practice. This study was conducted to analyze the particle characteristics of Aeolian sand deposits in Yulin area to improve the confidence for its use as a subgrade or fine aggregate material in road construction. Based on the findings of this limited study, the following conclusions are drawn:

(1) The particle sizes of the Aeolian sand in Yulin are mainly distributed between $0.075 \mathrm{~mm}$ and $0.3 \mathrm{~mm}$ and have very low clay content (less than $11 \%$ ). The samples collected from locations closer to Inner Mongolia are coarser and contain much lower clay content than those from Jingbian area. In road construction, soils with higher clay content are undesirable because they provide lower bearing capacity to support the upper road layers. However, because of the much lower clay content in the Aeolian sand of Yulin, it is possible to achieve the required bearing capacity if used as a subgrade material.

(2) The surface microstructure of the wind-deposited sand particles in Yulin has three different types of shapes: Pit-shaped, disc-shaped, and serpentineshaped. Pitting on the surfaces of Aeolian sand particles leads to the formation of more rounded and spherical grains.

(3) More than $95 \%$ of the mineral components of the Aeolian sand particles are quartz and feldspar. The quartz content in the $0.5 \mathrm{~mm}-1.0 \mathrm{~mm}$ Aeolian sand is $10 \%$ higher than that in the other three particle sizes. Other mineral components such as chlorite and calcite which are known to be detrimental to concrete or mortar were also present but only in negligible amounts. Therefore, mineralogically, the Aeolian sand particles can be safely used in preparing concrete or mortar for road construction without causing any potential complex chemical reactions.

(4) The gradation curves of the circular mesh sieve samples are very identical, while the curves of the square mesh sieve samples showed obvious differences. Intensive pitting on the surface of Aeolian sand can cause the rapid formation of rounded particles. With the prevalence of rounded spherical grains in the Aeolian sand from the six different locations, the use of round mesh sieve may not be 
ideal for distinguishing their particle size gradation. On the other hand, a square mesh sieve was found to be more effective in providing clear distinction on the gradation of Aeolian sand samples collected from the different locations within Yulin. As a result, the square mesh sieve is preferred over the round mesh for characterizing the particle size distribution of the sand deposits.

(5) With the square mesh sieve as the preferred sieve, gradation curves were generated for all the collected Aeolian sand samples. It was observed from the gradation curves that the slopes dramatically changed at the $0.15 \mathrm{~mm}$ sieve line. Also, the percentage passing rate at this point ranged from $7 \%$ to $95 \%$ for all the samples. Therefore, using the percentage passing rate in the $0.15 \mathrm{~mm}$ sieve as a classification index, the Aeolian sand particles were theoretically classified into three categories: Class A (passing rate is less than 30\%), Class B (passing rate between $30 \%-60 \%$ ), and Class $C$ (passing rate is more than $60 \%$ ).

(6) A plot of fineness modulus versus percentage passing in $0.15 \mathrm{~mm}$ sieve showed good linear correlation, which indicates that the fineness modulus of the different classes of Aeolian sand particles is sufficient for characterizing their engineering properties. Aeolian sand particles with higher pass rates in the $0.15 \mathrm{~mm}$ sieve tend to have smaller fineness modulus, while those with higher fineness modulus have lower pass rates.

\section{Data Availability}

The data used to support the findings of this study are included within the article.

\section{Conflicts of Interest}

The authors declare that they have no conflicts of interest.

\section{Acknowledgments}

This work was granted by Key laboratory of Degraded and Unused Land Consolidation Engineering, the Ministry of Land and Resources (Grant no. SXDJ2018-14). The authors are grateful to their funding support.

\section{References}

[1] F. Cain, "What percentage of the earth's land surface is desert?," Available: https://www.universetoday.com/65639/ what-percentage-of-the-earths-land-surface-is-desert/, 2010.

[2] D. Rechtschaffen, "How China's growing deserts are choking the country," Available: https://www.forbes.com/sites/ danielrechtschaffen/2017/09/18/how-chinas-growingdeserts-are-choking-the-country/?sh=7877608c5d1b, 2017.

[3] C. Li, D. Yao, S. Liu et al., "Improvement of geomechanical properties of bio-remediated aeolian sand," Geomicrobiology Journal, vol. 35, no. 2, pp. 132-140, 2018.
[4] R. Bagnold, The Physics of Blown Sand and Desert Dunes, Springer, Berlin, Germnay, 1 ed. edition, 1941.

[5] J. F. Kok, E. J. R. Parteli, T. I. Michaels, and D. B. Karam, "The physics of wind-blown sand and dust," Reports on Progress in Physics, vol. 75, no. 10, Article ID 106901, 2012.

[6] K. Pye and H. Tsoar, "Characteristics of windblown sediments," in Aeolian Sand and Sand Dunes, K. Pye and H. Tsoar, Eds., Springer Berlin Heidelberg, Berlin, Germany, pp. 51-97, 2009.

[7] M. G. M. Elipe and S. López-Querol, "Aeolian sands: characterization, options of improvement and possible employment in construction - the state-of-the-art," Construction and Building Materials, vol. 73, pp. 728-739, 2014.

[8] D. Zhenghu, X. Honglang, D. Zhibao, W. Gang, and S. Drake, "Morphological, physical and chemical properties of aeolian sandy soils in northern China," Journal of Arid Environments, vol. 68, no. 1, pp. 66-76, 2007.

[9] M. Al-Ansary, M. C. Pöppelreiter, A. Al-Jabry, and S. R. Iyengar, "Geological and physiochemical characterisation of construction sands in Qatar," International Journal of Sustainable Built Environment, vol. 1, no. 1, pp. 64-84, 2012.

[10] G. P. Padmakumar, K. Srinivas, K. V. Uday et al., "Characterization of aeolian sands from Indian desert," Engineering Geology, vol. 139-140, pp. 38-49, 2012.

[11] A. J. Al-Taie, Y. J. Al-Shakarchi, and A. A. Mohammed, "Investigation OF geotechnical specifications of sand dune soil: a case study around baiji in Iraq," IIUM Engineering Journal, vol. 14, 2013.

[12] E.-S. Seif, "Performance of cement mortar made with fine aggregates of dune sand, kharga oasis, western desert, Egypt: an experimental study," Jordan Journal of Civil Engineering, vol. 7, 2013.

[13] B. Nzuki, L. Luo, P. Zhou, C. Niyonzima, and X. Tu, "Mineralogical characterization of aeolian sands from inner Mongolia, China," Journal of Minerals and Materials Characterization and Engineering, vol. 7, pp. 81-102, 2019.

[14] M. M. Abu-Zeid, A. R. Baghdady, and H. A. El-Etr, "Textural attributes, mineralogy and provenance of sand dune fields in the greater Al Ain area, United Arab Emirates," Journal of Arid Environments, vol. 48, no. 4, pp. 475-499, 2001.

[15] N. Lancaster, Geomorphology of Desert Dunes, Taylor and Francis e-Library, New York, NY, USA, 2005.

[16] M. I. El-Sayed, "Sedimentological characteristics and morphology of the aeolian sand dunes in the eastern part of the UAE, a case study from Ar Rub' Al Khali," Sedimentary Geology, vol. 123, no. 3-4, pp. 219-238, 1999.

[17] Y. Yuan, X. Wang, and X. Zhou, "Experimental research on compaction characteristics of aeolian sand," Frontiers of Architecture and Civil Engineering in China, vol. 2, no. 4, pp. 359-365, 2008.

[18] H. Zhang, Z. Y. Wang, R. X. Liu, and L. Li, "Study of static mechanical properties of aeolian sand," Applied Mechanics and Materials, vol. 587-589, pp. 976-980, 2014.

[19] G. Zhang, J. Song, J. Yang, and X. Liu, "Performance of mortar and concrete made with a fine aggregate of desert sand," Building and Environment, vol. 41, no. 11, pp. 1478-1481, 2006.

[20] A. S. Al-Harthy, M. A. Halim, R. Taha, and K. S. Al-Jabri, "The properties of concrete made with fine dune sand," Construction and Building Materials, vol. 21, no. 8, pp. 1803-1808, 2007.

[21] E.-S. S. A. Seif, "Assessing the engineering properties of concrete made with fine dune sands: an experimental study," 
Arabian Journal of Geosciences, vol. 6, no. 3, pp. 857-863, 2013.

[22] F. J. Luo, L. He, Z. Pan, W. H. Duan, X. L. Zhao, and F. Collins, "Effect of very fine particles on workability and strength of concrete made with dune sand," Construction and Building Materials, vol. 47, pp. 131-137, 2013.

[23] C. N. Standards, Test Methods of Aggregate for Highway Engineering, Code of China, Beijing, China, 2005.

[24] C. N. Standards, Standard For Engineering Classification Of Soil, The Standardization Administration of the People's Republic of China, Beijing, China, 2007. 